-ORIGINAL ARTICLE-

Volume 15 Issue 22020

DOI: 10.21315/aos2020.15.2.463

ARTICLE INFO

Submitted: $17 / 04 / 2020$

Accepted: 18/10/2020

Online: $24 / 12 / 2020$

\section{Dental Students' Perceptions of Learning Space: A Focus Group Study}

\author{
Lau May Nak*, Saritha Sivarajanna, Zamros Yuzadi Mohd Yusof ${ }^{b}$ \\ ${ }^{a}$ Department of Paediatric Dentistry and Orthodontics, Faculty of \\ Dentistry, University of Malaya, 50603 Kuala Lumpur, Malaysia \\ ${ }^{b}$ Department of Community Oral Health and Clinical Prevention, \\ Faculty of Dentistry, University of Malaya, 50603 Kuala Lumpur, \\ Malaysia
}

*Corresponding author: minalau@um.edu.my

To cite this article: Lau MN, Sivarajan S, Yusof ZYM (2020). Dental students' perceptions of learning space: A focus group study. Arch Orofac Sci, 15(2): 175-185. https://doi.org/10.21315/ $\operatorname{aos} 2020.15 .2 .463$

To link to this article: https://doi.org/10.21315/aos2020.15.2.463

\begin{abstract}
Optimal learning space enhances teaching and learning experience and may differ from one discipline to another. This research aimed to explore the opinions on learning spaces for teaching and learning orthodontic course among recent dental graduates. Focus group discussions (FGD) were conducted in 2018 with two groups of recent graduates (eight participants per group) based on their orthodontic examination results (high and low grades). They were asked to give their opinions on the learning space provided for orthodontic lectures, tutorials, clinics, self-study and networking. Discussions during the FGD were audio and video recorded. Data were transcribed and thematically analysed using the NVivo version 12 software. For lectures, the graduates preferred a conventional lecture hall layout with an individual power outlet and a desk large enough for a laptop. For tutorials, the graduates with higher grades preferred e-tutorials while the graduates with lower grades preferred the conventional tutorials. For clinical teaching, the graduates perceived the laboratory's operating hours as limited and suggested a $24-\mathrm{h}$ access card. The graduates preferred live-streaming sessions instead of on-site teachings for combined clinics. They also felt that they do not have time for self-study and networking during their time in the campus. The findings of the study showed that learning space preferences of undergraduate dental students for lecture, tutorial, clinic, self-study and networking were more focused towards their learning activities, which were different from the current concept of learning space. Future planning of learning space should consider students' preferences in order to fulfil their learning goals.
\end{abstract}

Keywords: Dental education; focus group; learning space; orthodontics; teaching and learning

\section{INTRODUCTION}

Learning space is defined as face-to-face, collaborative and technology enabled learning environments (Oblinger, 2005; Joint Information Systems Committee, 2006). Impacts of learning space on the teaching and learning experience have long been highlighted in the report by the Joint Information Systems Committee (2006) and the Scottish Funding Council (2006). Providing a variety of conducive learning spaces enabled students to work and socialise together to achieve the set learning goals (Kuh et al., 2005). Learning space has evolved from the traditional classroom to the technology-rich active learning space with flexible furniture to promote student-teacher and student-student interactions. Though the definition has not been laid out clearly, this 
current concept of learning space, sometimes referred to as interactive learning space (ILS), which utilises flexible furniture and technology to promote interactions in the classroom is now emerging slowly. The use of technology may range from replacing the conventional whiteboard with an interactive whiteboard to a highly technology-rich setting including virtual learning space (Vercellotti, 2018). Nevertheless, it was noted that optimal learning spaces may differ from one discipline to another (Beckers, 2016). Besides, learning space preferences of higher education students mainly result from their learning goals and evolving study activities (Scottish Funding Council, 2006; Beckers, 2016). It is suggested that further research should involve different disciplines and identify differences in the preferences of learning space between countries (Beckers, 2016). Thus, this research aimed to explore the opinions on learning space for teaching and learning orthodontic course among recent dental graduates. The study chose recent dental graduates because they had experienced the full extent of the 5-year undergraduate curriculum delivered in the latest learning space at the faculty.

\section{MATERIALS AND METHODS}

\section{Study Design and Study Population}

Ethical approval for this study was obtained from the Medical Ethics Committee, Faculty of Dentistry, University of Malaya (DF CD1901/0001[L]). This study employed a qualitative approach to explore graduates' opinions on learning space preferences for teaching and learning orthodontic course. The study population was recent dental graduates from the Faculty of Dentistry, University of Malaya who had experienced the full extent of the 5-year undergraduate curriculum delivered in the latest learning space at the faculty. We used focus group discussion (FGD) as the method for data collection (Rees et al., 2002; Hannes et al., 2008). In this method, a small group of participants with similar backgrounds were gathered to discuss a specific topic in English. Their responses were obtained through semistructured group interviews facilitated by a moderator. This method was useful to obtain detailed information about the graduates' opinions on the learning spaces for teaching and learning orthodontic course at the faculty.

\section{Development of FGD Questions and Training of the Moderator}

A series of discussions among academics in the field of orthodontics at the faculty was held to develop the FGD questions. The questions were developed specifically to obtain participants' feedback on the current learning spaces at the faculty for studying the orthodontics course. After the development of the questions, training for the FGD moderator (LMN) and the note taker (SS) was conducted by an expert in the methodology of qualitative research (ZYMY). This was to ensure standardised ways of asking questions and probing for answers by the moderator were adopted. On the other hand, the note taker was also trained to take relevant notes during FGD sessions. Next, a pilot FGD was conducted with a group of undergraduate students. The aim was to assess the questions in terms of clarity and word appropriateness. At the same time, an evaluation of the implementation process and the time taken to conduct the FGD in the field conditions were also carried out. Following the pilot FGD, some minor corrections to the questions were made according to the students' feedback.

\section{Sampling and Recruitment}

The study sample consisted of dental graduates of 2018 from University of Malaya. The recruitment was based on their final year orthodontic examination results. Two groups of graduates (eight participants per group) were chosen based on their examination grades. Group 1 consisted of eight graduates with higher grades (scores ranging from $75.13 \%$ to $85.76 \%$ ) and Group 2 consisted of eight graduates with lower grades (scores 
ranging from $50.58 \%$ to $59.64 \%$ ). Based on our observation, students with lower grades might be timid to express their opinion when they were placed in the same group with students of higher grades. By separating the graduates with higher grades from those with lower grades, the study was able to explore the potential differences in their opinions. The size of the group was determined so that the FGD was small enough to allow all graduates to share their opinions, and yet large enough for diversity (Fusch and Ness, 2015). The eligible graduates were contacted and those who volunteered to participate in the study were invited to attend the FGD on a specific date, time and location.

\section{Conduct of FGD Sessions and Data Analysis}

The two FGD sessions with Groups 1 and 2 were conducted in a meeting room at the Faculty of Dentistry, University of Malaya. Each FGD session covered a number of distinct sections: welcoming note by the moderator, an introduction to the FGD, anonymity of responses, ground rules, warm-up session, clarification questions, key questions, concluding question and conclusion (Vaughn et al., 1996). The primary purpose of this guide was to act as a memory aid for the moderator and as a standardisation method for the FGD. The main topic guide consisted of five openended questions related to learning spaces for orthodontic lecture, orthodontic tutorial, orthodontic clinic, self-study and networking. Each question was discussed until data saturation was reached before moving on to the next question (Guest et al., 2006; Williams and Jeanetta, 2016). The respective questions were as follows:

1. What are your opinions on the space and infrastructure provided for orthodontic lecture?

2. What are your opinions on the space and infrastructure provided for orthodontic tutorial?
3. What are your opinions on the space and infrastructure provided for orthodontic clinic?

4. What are your opinions on the space and infrastructure provided for self-study?

5. What are your opinions on the space and infrastructure provided for networking and group work, e.g., group assignments?

6. Is there anything you wish to add further based on the questions we asked earlier?

At the beginning of the session, a written informed consent and personal information of the participants, i.e., name, age, gender and ethnicity were obtained. Next, the moderator introduced herself to the group and explained about the FGD process, which includes an explanation on the FGD concept and keywords, anonymity and ground rules. The participants introduced themselves to the group to get to know each other before the discussion began.

The moderator began by asking the first question to the group. This was followed by a group discussion among the graduates until the graduates' opinions on the topic had been fully explored. Next, the moderator would ask the second question followed by a group discussion. The process continued until all the six questions had been asked and deliberated by the participants fully. Both FGD sessions were recorded using audio and video recording tapes. The questions were also projected on a screen, which was visible for all the graduates during the FGD to serve as a group memory for the participants. The attendance sheet was used to refer to specific graduates whenever there was a need for further clarification. In each session, the moderator was in charge of facilitating the group discussion, keeping the group focused on the topic of discussion whenever needed, and making sure balanced input was obtained from all participants. The note taker was responsible for handling the attendance sheet, timekeeping, audio recording, making sure the discussions were recorded by a technical assistant using a 
video recorder, assisting the moderator, and noting down the important contextual notes throughout the discussion.

For data analysis, the audiotaped discussions were transcribed verbatim. The transcripts were thematically analysed using a qualitative data analysis software, NVivo ${ }^{\mathrm{TM}}$ Version 12 (QSR International Pty Ltd., Australia) to generate relevant themes for each of the questions. This was followed by the identification of information units from the transcripts in order to categorise the information units into the different themes generated. Information unit is defined as the smallest amount of information that is informative by itself (Rees et al., 2002). All analyses were carried out by two investigators (LMN and SS) independently before comparing the themes for interrater reliability. Finally, triangulation of data analysis was completed by employing a third person (ZYMY) who analysed the data transcriptions, the emerging themes and information units independently to improve rigour of data. Any slight differences in the themes were solved through discussions between the assessors.

\section{RESULTS}

\section{Participant Characteristics}

A total of 16 recent graduates participated in the FGD. Their age ranged from 24 to 25 years (mean age $=24.06$ years old $\pm 0.24)$. There were more female $(75 \%$, $n=12)$ than male graduates $(24 \%, n=4)$ with equal distribution of Malay and Chinese ethnicities.

\section{Learning Space for Orthodontic Lecture: Graduates Preferred a Conventional Lecture Hall Layout with an Individual Power Outlet and a Desk Large Enough for a Laptop}

All graduates except one, commented that they preferred a conventional lecture hall for receiving didactic lectures. They felt a conventional lecture hall layout enabled them to focus on the lecture content and the knowledge delivered. The graduates, among others, had commented as follows:

I prefer conventional lecture hall because we are sitting in a more formal setting to allow everyone to pay attention to the lecture. I do not like to be seated in groups during lecture as some of us might make some noise, for example talking to each other. It disturbs others and we can't focus on the lecture. (Respondent 1, Group 1)

I prefer the conventional type because it helps the students to focus on the lecturer. (Respondent 7, Group 1)

Most graduates preferred a conventional lecture hall with a dim lighting and a pitched floor with tiered seating. In addition, they also preferred to have an individual power outlet for each seat, and a sturdy foldable desk attached to the chair which is large enough to support a laptop.

Some of us will bring laptops to the lecture hall but we cannot charge our laptops because there is no plug point nearby our seats. We like to sit in the middle of the lecture hall but the socket is on the wall so it's not so convenient for us. (Respondent 8, Group 1)

All our lecture notes can be downloaded before the lecture begins which is very good. I see some of my friends jot down notes in the lecture notes they downloaded, so it's very convenient. If the table is not so flimsy but more sturdy, bigger and wider, I think it's a very good thing for us. (Respondent 8, Group 1)

There was one graduate who preferred a more interactive and technology-enhanced active learning space. However, it was solely because of the fact that it enables students to bring their own laptop with easy to reach power outlets to charge their laptops. 


\section{Learning Space for Orthodontic Tutorials: Graduates with Higher Grades Preferred E-Tutorials while Graduates with Lower Grades Preferred Conventional Tutorials}

Graduates with lower grades preferred conventional tutorials while graduates with higher grades preferred e-tutorials. Graduates who preferred a conventional tutorial commented that there was a lack of interaction on e-tutorial. They preferred a conventional tutorial as it allowed them to ask questions and receive immediate feedback from the lecturer. Graduates who preferred e-tutorial liked the concept as it allowed them to ask questions freely without having to raise their hands or face their lecturer. E-tutorial also encourage active learning, and they could always reread the part that they did not understand. The following are some verbatim statements from the graduates in the higher-grade group who preferred the e-tutorials:

E-tutorial is a good way because everyone has to try to understand the topic in order to do the assignment rather than just sit back and listen to others. (Respondent 2, Group 1)

Some questions we will feel like quite stupid to ask but in that platform, we dare to ask because we can just type without facing the lecturer. (Respondent 4, Group 1)

I kind of like the e-tutorial because I can always read back about the part that I don't understand. (Respondent 6, Group 1)

There were two graduates in the highergrade group who suggested the combination of both conventional and e-tutorials. One of them has the following comments:

We once had both conventional tutorial and e-tutorial for the same topic. On the online platform, we were given one or two weeks to answer the questions and submit our answers. Then, we can have a discussion during the conventional tutorial on what we had answered during the e-tutorial. (Respondent 1, Group 1)

\section{Learning Space for Orthodontic Clinic: Graduates Perceived the Laboratory Operating Hours as Limited}

Orthodontic teaching for undergraduate students involves the clinical teaching as well as the practical skills such as wirebending and the construction of orthodontic removable appliances for patients. These appliances were constructed in the laboratory by the students. To increase the usage of the laboratory facilities, the graduates had suggested a $24 \mathrm{~h}$ access card to the laboratory facilities using a special access card. Apart from that, the graduates had suggested having a staff on duty specifically for orthodontic discipline, and also to have a separate laboratory for the orthodontic discipline. Following are some verbatim statements from the graduates:

I would love to have a laboratory that is accessible for $24 \mathrm{~h}$. (Respondent 3, Group 2)

We are busy with clinics during office hours, unfortunately, when we are free after clinics, the laboratory is closed as well, and we can't assess the lab. Would be nice to have laboratory accessible beyond office hours with a special access card. (Respondent 1, Group 2)

Since we can't access the laboratory after office hours, we rush to do lab work whenever we don't have patient in clinic, and during our lunch break when we are back at the lab as well. (Respondent 4, Group 1)

We have to skip our meals as the schedules are too tight, I wish to have $24 \mathrm{~h}$ access card to the laboratory. (Respondent 2, Group 2) 


\section{Learning Space for Orthodontic Clinic: Graduates Preferred Live Streaming Sessions Instead of On-Site Teachings for Combined Clinics}

The final year dental students were also required to attend cleft and orthognathic combined clinics as part of the multidisciplinary management plan for patients with cleft and jaw discrepancies who require corrective surgeries. The graduates felt that their learning experiences at the cleft and orthognathic combined clinic were ineffective as the clinics were too crowded. The graduates also felt that patients were often intimidated by the presence of many undergraduate students as observers in the clinic, which compromised doctor-patient interactions. Graduates from the lower grade had commented as follows:

Sometimes, we don't know what we are seeing. (Respondent 3, Group 2)

It's crowded, very crowded. We can't even see the patient, we just observe, no opportunity to discuss and ask questions as the clinic is fully booked with appointments. (Respondent 6, Group 2)

Thus, the graduates preferred to learn from a live-streaming demonstration during the combined clinics for an effective teaching and learning experience at the school. Such way of learning can also protect the patient's privacy. A graduate with a higher grade suggested that:

Maybe our group can take turns to observe one case instead of all going in together or we can discuss the case later after the combined clinics. We can even have a smart board that displays patient's history, pictures and the plan for the day. Or, we can also have a live video feed of the combined clinics, so we can watch from another room, is it possible? (Respondent 4, Group 1)
Another graduate suggested that:

A live streaming during the combined clinic with a moderator would be nice as we can ask questions to the moderator (the specialist) and this session can be an interactive learning. (Respondent 8, Group 1)

\section{Learning Space for Self-Study: Graduates Perceived They Do Not Have Time for Self- Study during Their Time in the Campus}

All graduates perceived that they do not have time for self-study during their time in the campus. The graduates commented that:

Actually, we don't have time for selfstudy in the faculty. (Respondent 6 , Group 2)

\begin{abstract}
We just sit anywhere to discuss and we don't have time and suitable place to study. (Respondent 7, Group 2)
\end{abstract}

\section{Learning Space for Networking: There is a Lack of Time for Networking during Their Time in Campus}

The main hurdle for students to do group work and networking in the learning space was lack of time due to their packed clinical schedules. The graduates perceived that there is a lack of time for networking. A graduate commented that:

We just sit anywhere to discuss as we can't find a suitable time to go to the student centre and the student centre closes at $5 \mathrm{pm}$. (Respondent 6, Group 2)

Another graduate responded that:

We are free for networking after our clinics at $5 \mathrm{pm}$. We can't access the faculty building to do any group discussion after this time. So, we think probably can extend the operating time until $10 \mathrm{pm}$. By extending the time to access the facilities at the faculty, we can get time for networking with our 
group mates to complete the task for tutorial and other activities. (Respondent 8, Group 1)

\section{DISCUSSION}

The findings from the FGD revealed the graduates' opinions on the current learning spaces provided for orthodontic lectures, tutorials, clinics, self-study and networking. It was found that learning space preferences for studying orthodontic course were specific to their learning needs and were different from the current concept of learning space (Scottish Funding Council, 2006; Beckers, 2016).

Similar to findings by Beckers (2016), our graduates perceived that functional attributes of a learning space were more important than the aesthetic attributes to support their learning activities. Examples of functional attributes of a learning space that were important for students include adequate lighting, comfortable temperature, functional furniture, adequate resources, and convenience for collaborative activity (Beckers, 2016). Our findings were consistent with the report by Scottish Funding Council (2006) and Beckers (2016) where learning space preferences were specific to learning activities and may differ from one discipline to another. Learning space preferences of our dental graduates for lectures, tutorials, clinics, self-study, and networking were specific to their learning activities and were different from the current concept of learning space (Vercellotti, 2018). This was shown when the graduates discussed learning space for the purpose of lecture in the FGD. Surprisingly, our graduates preferred a traditional lecture hall layout to an active learning space with flexible furniture despite the graduate's experience using it in the Faculty of Medicine, University of Malaya since 2015. The active learning space in the Faculty of Medicine, known as the CUBE, is a learning space equipped with the flexible furniture for different configuration of settings to accommodate classrooms of different sizes and different teaching and learning methods. It is also equipped with high-tech devices such as audio and video tools, telecommunication system, public address system and information technology system to enhance the teaching and learning experience. It is named as CUBE because the original design of the learning space was cube in shape. Although our students used both the traditional lecture hall and the CUBE during their five academic years, they utilised the traditional lecture hall more frequently. Familiarity of the students and the teachers with the new learning space may influence the experience of users (Gordy et al., 2018). Nevertheless, there is a need to upgrade the lecture hall to be a technology-rich learning environment while maintaining the features of a traditional lecture hall that the students preferred. Being the Generation Z (those who were born between 1995 and 2015), our graduates expressed their wishes of having an individual power outlet and a foldable desk large enough to support a laptop at each seat. The need for these facilities has evolved with the current generation being more familiar with technology-rich learning environments than previous generations.

The Scottish Funding Council (2006) introduced seven types of learning spaces for higher education facilities. For group teaching and learning, it is recommended to have flexible furniture arrangements to accommodate groups of varying sizes and using varying layouts, preferably in square rather than the rectangular rooms as the former was more adaptable. It is important to note that different types of learning spaces may be needed for different subjects (Scottish Funding Council, 2006). In comparison to the current concept of learning space suitable for group teaching, i.e., an interactive and technology-enhanced learning space, our final year dental students preferred a conventional lecture hall instead. There is no need for a flexible furniture arrangement to accommodate groups of varying sizes, as the total number of dental student intakes each year is consistent at 50 students per year. 
Despite being relevant to most undergraduate dentistry courses, a large lecture class is often criticised as a teachercentred rather than student-centred teaching method (Muganga and Ssenkusu, 2019). However, other student-centred learning methods are available to encourage critical thinking and higher levels of learning, i.e., tutorials, problem-based learning, case-based learning and clinics.

Our findings on the students' preference to receive lectures in the lecture hall is in contrast with the findings by Gordy et al. (2019) who reported that dental hygiene students preferred a technology-rich active learning classroom with movable furniture over a traditional classroom. It was reported that the students especially enjoyed the spaciousness, mobility, unobstructed view, ease of information-sharing and levels of engagement in class. However, the active learning classroom also affects students with sensory and technique challenges i.e., the students can be distracted by the enhanced sensory stimulation and it requires students to have the technical skills to follow the class (Gordy et al., 2019). Although students preferred an active learning classroom, the advantage was not reflected in terms of improvement in the examination grades (Gordy et al., 2018). However, the duration of use and familiarity of the students and the teachers with the new learning environment is another influencing factor. Improved experience with the new learning environment might lead to a more promising outcome on the teaching and learning effectiveness in the long term (Gordy et al., 2018). Thus, there is a need to look into the pros and cons of the conventional lecture hall, and the modern interactive learning space, as well as its relevance and efficiency in teaching undergraduate dentistry course. Combining the learning space features that are essential for students and customising a design to meet their specific need is preferred by the dental students.

Tutorial encourages critical thinking and higher learning level through group assignments and discussion. Interestingly, we found that the graduates with lower grades preferred conventional tutorial while the graduates with higher grades preferred e-tutorial. Students who preferred conventional tutorial commented that there was a lack of group interaction in e-tutorial. They preferred conventional tutorial as it allowed them to ask questions and receive immediate feedback from the lecturer. Students who preferred e-tutorial liked it as it allowed them to ask questions freely without having to raise their hands or face the lecturer. Furthermore, they could always revisit the part that they did not understand, and this encouraged active learning. Two graduates from the group with higher grades suggested to combine both conventional tutorials and e-tutorials. If carried out systematically for every topic, this combined method may improve the students' teaching and learning experience, which helps promote efficiency. This teaching method is called blended learning. It is defined as "the thoughtful integration of classroom face-toface learning experience with online learning experiences" by "integrating the strengths of synchronous (face-to-face) and asynchronous (text-based internet) learning activities" (Garrison and Kanuka, 2004).

One of the challenges faced by healthcare profession educators is to create an optimal clinical learning environment in order to enhance students' learning outcomes (Ebbeling et al., 2018). Research has shown that the clinical component of dental education is stressful for students as a high level of supervision and studentteacher interaction are needed in the clinic (Anderson et al., 2011). Thus, an optimal clinical learning environment is vital to achieve students' learning goals for the clinical component and enhance students' learning experience. A live-streaming demonstration in a separate learning space with a facilitator present not only solves the visibility problem but also enhances close and active interactions between the teacher and the students (Goffe and Sosin, 2005). 
Self-study is an important aspect of effective learning in higher education. Thus, we explored graduates' opinions on learning space for self-study. All graduates perceived that they did not have time for self-study during their time in campus. This result is not unexpected in view of the students' heavy clinical schedule. Besides lectures, tutorials, and other types of teaching and learning activities, undergraduate dental students also have clinical and laboratory work which take up most of their time, in addition to group assignments and selfstudy. A previous qualitative investigation revealed that the students preferred to have a space for personal work within the dental school (The et al., 2018). There is a need to provide a suitable learning space for selfstudy in the faculty. However, it is only useful and impactful if a sufficient duration of designated self-study time can be allocated in the schedule.

Much of effective learning, particularly informal learning takes place as a result of interactions between students. By providing a variety of conducive spaces that enable and encourage students to work and socialise together, the learning goals can be achieved (Kuh et al., 2005). Students preferred to have a space for collaborative work within the dental school (The et al., 2018). However, unless students were given sufficient time for networking and group work during their time in campus, such facilities may not be impactful to the students.

The findings of the study help us to understand the interrelationship between study activities and preferences for the learning space for such activities. Information gained from this research can be used to help evidence-based decision-making in terms of improving the current learning space or designing a new learning space that is specific to dental students' needs in order to enhance teaching and learning efficiency.

Questionnaires can be developed from the FGD outputs, which can be used to obtain quantitative feedback from existing and future students. Once validated, the questionnaire can be used to evaluate the impact of current learning spaces on the students' teaching and learning experiences including their improvements to suit students' preferences and satisfaction in fulfilling their learning goals.

\section{LIMITATIONS OF THE STUDY}

This study has a few limitations that might reduce the generalisability of the study findings. Firstly, only 16 graduates were included in the FGD. Although this number is relatively smaller than the other studies, it was considered adequate as the sample represented $32 \%$ of the graduates (16/50 graduates). Besides, we included graduates with higher and lower examination grades in the study to ensure diversity in the sampling. Furthermore, each question was discussed thoroughly until data saturation had been achieved (Guest et al., 2006; Fusch and Ness, 2015; Williams and Jeanetta, 2016). Secondly, the sample only included recent graduates of 2018. However, the inclusion of previous batches of graduates was not feasible as the recent graduates were the ones who had experienced the latest learning space provided for teaching and learning the orthodontic course at the faculty.

\section{CONCLUSION}

Within the limitations of this study, the undergraduate dental students preferred a conventional lecture hall layout with an individual power outlet and a desk large enough for a laptop for receiving didactic lectures. Students with higher grades preferred e-tutorials while students with lower grades preferred conventional tutorials. Students preferred live-streaming sessions instead of on-site teachings for combined clinics. Planning for learning space should consider the students' preferences in order to fulfil their learning goals and enhance the teaching and learning experience. 


\section{ACKNOWLEDGEMENTS}

This study was funded by UM Learning Improvement and Teaching Enhancement Research (UMLiter Grant), University of Malaya (RU008AO-2017). The authors would like to acknowledge Mr. Mohammad Firdaus bin Abd Rahaman, our staff from the Faculty of Dentistry, University of Malaya for his generous help throughout this research.

\section{REFERENCES}

Anderson VR, Rich AM, Seymour GJ (2011). Undergraduate dental education in New Zealand: 2007-2009 final-year student feedback on clinical learning environments. NZ Dent F, 107(3): 85-90.

Beckers R (2016). Higher education learning space design: Form follows function? In: Nielsen SB, Jensen PA (eds.), Research Papers for EuroFM's 15th Research Symposium at EFMC2016. Lyngby: Polyteknisk Forlag, pp. 99-109.

Ebbeling S, Adam L, Meldrum A, Rich A, McLean A, Aitken W (2018). Oral health and dental students' perceptions of their clinical learning environment: A focus group study. $\mathcal{F}$ Dent Educ, 82(10): 1036-1042. https://doi.org/10.21815/ JDE.018.102

Fusch PI, Ness LR (2015). Are we there yet? Data saturation in qualitative research. Qual Rep, 20(9): 1408-1416.

Garrison DR, Kanuka H (2004). Blended learning: Uncovering its transformative potential in higher education. Internet High Educ, 7(2): 95-105. https://doi.org/10.1016/j. iheduc.2004.02.001

Goffe WL, Sosin K (2005). Teaching with technology: May you live in interesting times. F Econ Educ, 36(3): 278-291. https:// doi.org/10.3200/JECE.36.3.278-291
Gordy XZ, Zhang L, Sullivan AL, Bailey JH, Carr EO (2019). Teaching and learning in an active learning classroom: A mixedmethods empirical cohort study of dental hygiene students. F Dent Educ, 83(3): 342 350. https://doi.org/10.21815/JDE.019.026

Gordy XZ, Zhang L, Sullivan AL, Haynie L, Richards-Moore L, Bailey JH (2018). A multi-disciplinary empirical investigation of active learning classroom's effects on student learning. Interdiscip Educ Psychol, 2(1): 3. https://doi.org/10.31532/ InterdiscipEducPsychol.2.1.003

Guest G, Bunce A, Johnson L (2006). How many interviews are enough? An experiment with data saturation and variability. Field Methods, 18(1): 59-82. https://doi. org/10.1177/1525822X05279903

Hannes K, Norré D, Goedhuys J, Naert I, Aertgeerts B (2008). Obstacles to implementing evidence-based dentistry: A focus group-based study. $\mathcal{F}$ Dent Educ, 72(6): 736-744.

Joint Information Systems Committee (JISC) (2006). Designing Spaces for Effective Learning: A Guide to 21st Century Learning Space Design. Bristol: University of Bristol, JISC Development Group.

Kuh GD, Kinzie J, Schuh JH, Whitt EJ, Associates (2005). Student Success in College: Creating Conditions that Matter. San Francisco: Jossey-Bass.

Muganga L, Ssenkusu P (2019). Teachercentered vs. student-centered: An examination of student teachers' perceptions about pedagogical practices at Uganda's Makerere University. Cult Pedagog Inquiry, 11(2): 16-40. https://doi. org/10.18733/cpi29481

Oblinger D (2005). Leading the transition from classrooms to learning spaces. Educause Quarterly, 28(1): 14-18. 
Rees CE, Sheard CE, McPherson AC (2002). A qualitative study to explore undergraduate medical students' attitudes towards communication skills learning. Med Teach, 24(3): 289-293. https://doi. org/10.1080/01421590220134123

Scottish Funding Council (SFC) (2006). Spaces for Learning: A Review of Learning Spaces in Further and Higher Education. Edinburgh: SFC.

The AJM, Adam L, Meldrum A, Brunton P (2018). Dental students' and staff perceptions of the impact of learning environment disruption on their learning and teaching experiences. Eur F Dent Educ, 22(3): 151-159. https://doi.org/10.1111/ eje. 12293
Vaughn S, Schumm JS, Sinagub JM (1996). Focus Group Interviews in Education and Psychology. Thousand Oaks: Sage Publications, Inc.

Vercellotti ML (2018). Do interactive learning spaces increase student achievement? A comparison of classroom context. Act Learn High Educ, 19(3): 197-210. https://doi. org/10.1177/1469787417735606

Williams F, Jeanetta SC (2016). Lived experiences of breast cancer survivors after diagnosis, treatment and beyond: Qualitative study. Health Expect, 19(3): 631-642. https://doi.org/10.1111/ 